\title{
Importance of trophic information, simplification and aggregation error in ecosystem models
}

\author{
S. J. Metcalf ${ }^{1,2,3, *}$, J. M. Dambacher ${ }^{2}$, A. J. Hobday ${ }^{1,2}$, J. M. Lyle ${ }^{3}$ \\ ${ }^{1}$ School of Zoology and QMS, University of Tasmania, Private Bag 5, Hobart, Tasmania, Australia, 7001 \\ ${ }^{2}$ CSIRO Marine and Atmospheric Research, GPO Box 1538, Hobart, Tasmania, Australia, 7001 \\ ${ }^{3}$ Marine Research Laboratories, Tasmanian Aquaculture and Fisheries Institute, University of Tasmania, Private Bag 49, \\ Hobart, Tasmania, Australia 7001
}

\begin{abstract}
Ecosystem models are becoming increasingly important as pressure from fisheries intensifies and ecosystem-based fisheries management becomes more widely used. Trophic webs often form the basis of ecosystem models and ecosystem-specific dietary information is crucial for optimal model performance. This is particularly the case if model predictions are used in management decisions. The Tasmanian live fish fishery for banded morwong was used as a case study to investigate the importance of trophic information, model simplification and aggregation error on ecosystem model results. Dietary analysis of 6 commonly captured reef fish was undertaken. Significant trophic overlap was found between blue throat wrasse Notolabrus tetricus and purple wrasse N. fucicola, and banded morwong Cheilodactylus spectabilis and bastard trumpeter Latridopsis forsteri. Marblefish Aplodactylus arctidens and long-snouted boarfish Pentaceropsis recurvirostris had significantly different diets from other species studied. Using this information, a detailed qualitative model was produced and then simplified through the aggregation of variables. Variables were aggregated using 3 methods: Euclidean distance, Bray-Curtis similarity, and regular equivalence for inclusion in 3 simplified models. Variable aggregation is undertaken in many studies and may create aggregation error. Each aggregation method produced a different proportion of incorrect model predictions as a result of aggregation error. The model simplified using regular equivalence produced the least aggregation error and a web structure aligned with the dietary analysis. More widespread use of these methods in fisheries management should be considered.
\end{abstract}

KEY WORDS: Diet · Qualitative modelling $\cdot$ Model structure $\cdot$ Regular equivalence

Resale or republication not permitted without written consent of the publisher

\section{INTRODUCTION}

Ecosystem modelling is a tool used to understand and predict changes to community dynamics. These models are crucial to support sustainable fisheries at a time when pressure on oceanic resources is higher than ever (FAO Fisheries Department 2004). The inshore reefs of eastern Tasmania support a variety of invertebrate and scalefish fisheries, such as the high-value abalone and rock lobster fisheries, as well as lower value live fish fisheries for banded morwong Cheilodactylus spectabilis and wrasse Notolabrus spp. In many of these smaller fisheries, particularly those using gillnets, the capture of non-target species commonly occurs. For ex- ample, the banded morwong gillnet fishery captures a diverse range of both target and non-target species. Catch sampling of this fishery from 1993 to 2005 recorded almost 80 different species and species groups (e.g. crabs) (J. M. Lyle unpubl. data). Ecosystem models are necessary to investigate the effects of capture on these species and the ecosystem.

Ecosystem models may be quantitative or qualitative and can aid conventional stock assessment by providing information on the state of the system. Developing cost-effective ecosystem modelling techniques is vital to investigate the effects of changes on small-scale, low-value fisheries, such as the banded morwong fishery. Qualitative ecosystem models may be based on 
trophic or non-trophic information. They also require a smaller amount of data and are less costly to produce than quantitative models. These models can allow for a greater understanding of ecosystem dynamics (Puccia \& Levins 1985) which may be useful in the investigation of data-poor fisheries. In ecological studies, trophic linkages often form the backbone of ecosystem models. These linkages are commonly inferred from dietary analysis (Christensen \& Pauly 1992, Okey et al. 2004). The calculation of traditional metrics, such as dietary overlap and niche breadth using data collected from the focal system, can highlight important ecological factors including trophic guilds and ontogenetic variation (Munoz \& Ojeda 1998). This information can then be incorporated into ecosystem models. Different trophic web structure can result in different model predictions and may therefore have a large impact on research and management decisions (Pinnegar et al. 2005). This was demonstrated by Yodzis (2001) when studying the effect of seal culling on fisheries. One model suggested the fishery would benefit from a cull and another, which included different trophic linkages, did not support this conclusion. In order to produce model predictions that will be useful in resource management, the trophic web most closely aligned to the natural system should be used. Without this information, management strategies may be based on predicted responses that do not occur in the natural system or may not predict responses that do occur.

The inclusion of the entire food web into models may provide a more realistic view of the system than aggregated models. However, large complex models often contain too much uncertainty (Raick et al. 2006) for their use to be beneficial. Species aggregation is often necessary to provide useful predictions (Auger et al. 2000, Fulton et al. 2003, Raick et al. 2006). Many alternative methods of aggregating ecosystem variables may be used; for instance, in many studies using Ecopath (e.g. Christensen et al. 2003, Okey et al. 2004, Bulman et al. 2006) functional groups were aggregated according to the impact of commercial fisheries and life history characteristics such as size. In addition, variable aggregation may be based on turnover rates and stock size (Gardner et al. 1982) and, commonly, on the modeller's perception of the system (Luczkovich et al. 2002). In other studies, more mathematical approaches such as Bray-Curtis similarities (Bray \& Curtis 1957, Pinnegar et al. 2005), Euclidean distance (Sokal \& Sneath 1963) and regular equivalence (Luczkovich et al. 2003) have been used to aggregate large numbers of species into groups. In contrast to complex models, species aggregation for simplification may result in the model becoming oversimplified (Raick et al. 2006). In addition, following the aggregation of species in any model, parameter uncertainty may still remain due to the dynamic nature of the real world. A compromise between high uncertainty and oversimplification may therefore be necessary and can be achieved by reducing the rate of error between detailed and simplified model predictions.

Much discussion has occurred on the type and value of aggregation techniques (e.g. Raffaelli \& Hall 1992, Raick et al. 2006). This discussion has focussed on methods of aggregation such as 'perfect aggregation' in which the dynamics of the aggregated variable are consistent with the dynamics of the disaggregated variables (Iwasa et al. 1987). This method was later found to be too restrictive for many forms of ecosystem analyses and the focus shifted instead to the 'best approximate aggregation' where the minimum inconsistency of dynamics between aggregated and disaggregated variables was preferred (Iwasa et al. 1989). Minimum inconsistency was desired as the aggregation of variables may result in prediction error due to the loss of information from disaggregated to aggregated groups (Auger et al. 2000). For example, information regarding the specific prey items of each species in an aggregated variable may be lost. Error may also occur due to the aggregation of predators and their prey (Gardner et al. 1982, Fulton et al. 2003) and of variables with differing turnover times (O'Neill \& Rust 1979, Gardner et al. 1982). The importance of uncertainty due to aggregation error has been acknowledged (Gardner et al. 1982, Cale et al. 1983) yet is rarely discussed in modelling studies with aggregated variables. This is not a trivial problem, particularly if the models are then used to inform management decisions. In addition, alternative methods of aggregation may result in different levels of error. If we assume the disaggregated model is a reasonable representation of the ecosystem, the use of the aggregation method that creates the least error can increase the predictability of the model results.

Qualitative ecosystem models, using signed digraphs (Levins 1974, Levins 1975), may be used to generate hypotheses and guide further ecosystem studies. These models can also provide a means to analyse aggregation error and are a quick and efficient way to study ecosystem structure. Aggregation error must be investigated following the simplification of models through variable aggregation to ensure the model predictability is retained. As the use of ecological models in management requires the assumption that the model is a reasonable representation of the system, the production of simplified models with high certainty of prediction of disaggregated model results is important. This is also necessary to ensure the hypotheses generated can be of use to management.

Qualitative modelling was used to produce a detailed initial model on the basis of the ecosystem-specific dietary information obtained during this study. Dietary 
information was collected for banded morwong, blue throat wrasse Notolabrus tetricus, purple wrasse N. fucicola, bastard trumpeter Latridopsis forsteri, longsnouted boarfish Pentaceropsis recurvirostris and marblefish Aplodactylus arctidens. This information was required because there were very few published accounts of the diets of these reef fish. Furthermore, available studies do not include information on commonly caught size classes (Choat \& Clements 1992) or have low sample sizes for the species of interest (Fenton 1996, Bulman et al. 2001). The variables in this model were aggregated using Euclidean distance, Bray-Curtis similarity and regular equivalence, and included in 3 separate simplified models. Comparisons between qualitative models with and without variable aggregation can be used to assess the level of aggregation error produced by different methods. This study investigated the diets of 6 common reef fish and explored how this information may be utilised to construct ecosystem models using different methods of model simplification. While the models and variables aggregated in this study were based on trophic linkages, the methods of aggregation and investigation into aggregation error may be used for other types of data, such as turnover and production rates. This study also illustrates the power of qualitative analysis as a method of ecosystem investigation for small-scale fisheries.

\section{MATERIALS AND METHODS}

Fish collection and processing. Each of the 6 study species is commonly captured in the Tasmanian live fish fishery for banded morwong which uses large mesh nets of 115 and $140 \mathrm{~mm}$ stretched mesh. During onboard commercial catch sampling, banded morwong were found to constitute approximately $35 \%$ of the total numbers of fish caught (J. M. Lyle unpubl. data). Blue throat and purple wrasse, bastard trumpeter and long-snouted boarfish are byproduct species and constitute a further $19 \%$ of the catch. Marblefish is a bycatch species that comprises around $21 \%$ of the catch. Byproduct species are retained non-target species and in this fishery the commercial catch is restricted by species-specific size limits. In contrast, bycatch are species without commercial value and are not retained by fishermen.

All fish were collected using gillnets with stretched mesh sizes ranging between 64 and $140 \mathrm{~mm}$ to ensure that adequate sample sizes of each species were captured. Fish were collected from various sites within the same region as the commercial banded morwong fishery on the east coast of Tasmania (Fig. 1). Banded morwong were collected between 2004 and 2006, while all other species were collected in 2005-2006. A general under- standing of the overall diet is sufficient for many ecosystem models and therefore diet was not assessed by individual location or season. Each fish was measured (fork length), weighed and sexed prior to gut removal.

The contents of the entire gut (stomach and intestines) were collected for all species to ensure that no bias occurred between species with and without defined stomachs (e.g. marblefish). Each sample was stored in $70 \%$ ethanol, dried with a paper towel and weighed to the nearest $0.01 \mathrm{~g}$ prior to examination. The majority of fish examined (>90\% per species) had food in the gut and only these fish were included in the dietary analyses. Gut contents were passed through a $1 \mathrm{~mm}$ sieve and identified, where possible, to species level under a dissecting microscope. Individual prey groups were weighed separately to the nearest $0.01 \mathrm{~g}$ for each stomach.

The number of samples necessary to obtain an accurate estimate of species richness within the diet was investigated using sample-based rarefaction in EstimateS (Version 7.5.0). Species accumulation curves were calculated by re-sampling observed data. This established that the sample sizes utilised for each species were higher than the minimum required to closely approach the asymptote of the curve describing the number of prey items versus the number of samples (Colwell et al. 2004).

Diet indices. The percent number $(\% \mathrm{~N})$, percent weight $(\% \mathrm{~W})$ and percent frequency of occurrence

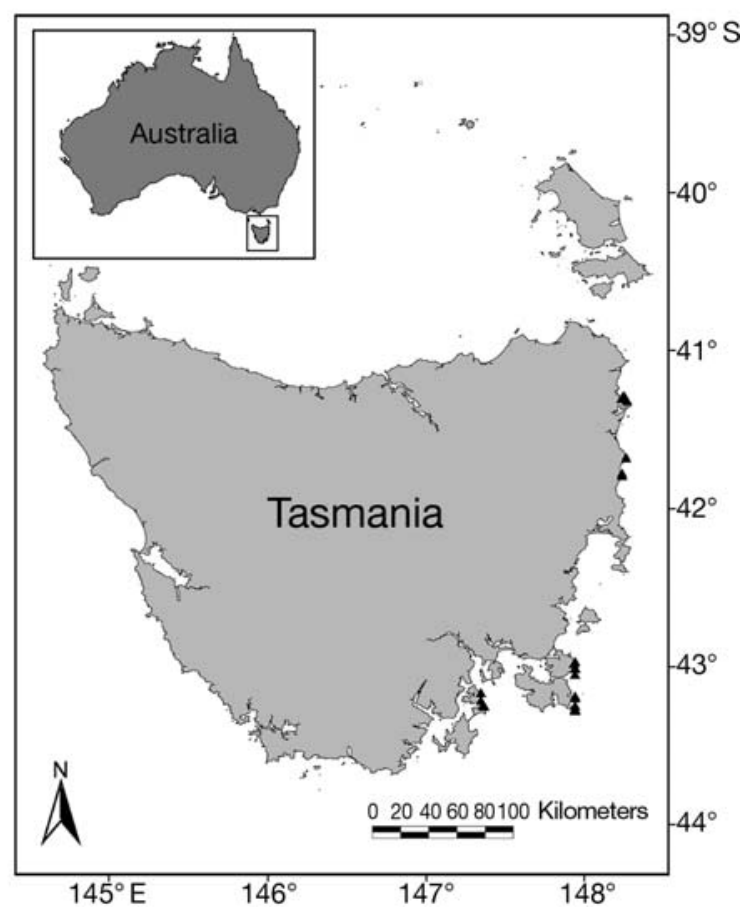

Fig. 1. Fish collection locations $(\boldsymbol{\Lambda}, \mathrm{n}=23)$ on the east coast of Tasmania during 2004-2006 
(\%FOO) were calculated in addition to the percent index of relative importance (\%IRI) (Hyslop 1980). The \%IRI was calculated as it may reduce potential biases caused by the use of a single metric. Prey items were grouped into higher taxa groupings (e.g. Order) to calculate the diet metrics. This was necessary to compare the diet composition between fish species. This also reduced bias between individuals with easily identifiable prey items and those in which prey were rarely identified (Cortes 1997).

Diet similarity and overlap. In order to determine the level of dietary similarity between species, multidimensional scaling (MDS) was undertaken using the prey type and number of prey items consumed. The data were square root transformed to reduce the effect of the dominance prey type and Bray-Curtis dissimilarities were used for MDS in Primer 5 (Version 5.2.9).

The simplified Morisita's Index (sensu Horn 1966) using $\% \mathrm{~W}$ was calculated to determine the level of overlap between species. Significant dietary overlap was assumed when Morisita's Index was greater than 0.6 (Wallace \& Ramsey 1983). Percent weight was used to determine which prey species should be included in the model as qualitative modelling and many types of ecosystem modelling are mass-based. Higher taxonomic groupings (Order and Family) were used for all overlap analyses.

Ecosystem models based on dietary information. Qualitative analysis was used to investigate ecosystem structure and aggregation error produced through different aggregation methods. Using qualitative analysis, the community can be represented by signed digraphs (Puccia \& Levins 1985), which are constructed using the signs $(+,-, 0)$ of the interactions $\left(\alpha_{i j}\right)$ between variables in the model. Negative effects are represented as links ending in closed circles while positive effects are shown as arrows. Links connecting the variable to itself represent density-dependence or resources external to the model that are constantly replenished in the system, such as phytoplankton. A signed digraph was used to construct a detailed initial model on the basis of dietary information obtained during the present study and from a review of the literature (Table 1). To ensure that the models did not become unwieldy with too many variables, only prey that constituted greater than $15 \% \mathrm{~W}$ per fish species were included in each model. This level of detail was selected because it includes the prey groups that constitute the majority of the diet for each species.

The simplification of the initial model was undertaken using the qualitative diet matrix to create 3 different models using Euclidean distance (ED), Bray-Curtis (BC) similarity and regular equivalence (RE) through the REGE algorithm (Luczkovich et al. 2003, www.analytictech. com/downloaduc6.htm). Similarity matrices were produced using these measures and these matrices were used to determine which variables to aggregate. Euclidean distance is the shortest distance between variables in ecological space (Sokal \& Sneath 1963). This distance measure does not take abundance into account and treats every number equally. Euclidean distance therefore measures presence and absence unlike Bray-Curtis similarity, which also measures magnitude through relative abundances in the data (Bray \& Curtis 1957). Neither Euclidean distance nor Bray-Curtis similarity can use the negative values produced as a result of the mortality of species through predation. In contrast, regular equivalence takes both predators and prey into account in the calculation of similarity (Luczkovich et al. 2003) but is not sensitive to relative abundances in the data. The REGE algorithm uses species-by-species matrices to calculate speciesby-species matrices of $\mathbf{R}$ coefficients which measure the regular equivalence between variables (Luczkovich et al. 2003). These coefficients have ordinal properties that may then be visualised using multivariate statistics.

A qualitative diet matrix was used in the calculation of Bray-Curtis similarities, Euclidean distance and regular equivalence, where the prey of a variable was denoted by a positive sign $(+1)$ and predators of the variable were denoted by a negative sign $(-1)$. This matrix was used instead of actual dietary metrics such as $\% \mathrm{~W}$ because we were interested in the qualitative presence/absence of linkages between species. Dendrograms were produced to display the similarity and distance measures for all 3 methods to visualise variable aggregations. The number of clusters selected for use in a model can be based on a desired level of equivalence or similarity among members of a cluster.

Table 1. References used for dietary information included in the initial model. A Tasmanian study was used in preference to other available information. (NA): unreported sample sizes

\begin{tabular}{|llcl|}
\hline Species & Location & Sample size (n) & Source \\
\hline Seals & Tasmania & 977 & Hume et al. (2004) \\
Gastropods & Tasmania & NA & Edgar (2000) \\
Decapods & New Zealand & 724 & Woods (1993) \\
Amphipods & Tasmania & NA & Edgar (2000) \\
Ophiuroids & Tasmania & NA & Edgar (2000) \\
Bivalves & Tasmania & NA & Edgar (2000) \\
Isopods & Tasmania & NA & Edgar (2000) \\
Polychaetes & South Australia & NA & Holloway \& Keough (2002) \\
& and Victoria & & \\
Sponges & Tasmania & NA & Edgar (2000) \\
Bryozoans & Western Australia & NA & Lisbjerg \& Petersen (2000) \\
\hline
\end{tabular}


The desired level of equivalence may vary given the questions being asked of the models, and when comparing between models, as in this study, the level of aggregation should be similar. If this does not occur, comparisons will be meaningless. In this study, models of 10 or 11 variables were selected for use as this level of aggregation remained biologically meaningful. In contrast, models of this system containing only 4 or 5 variables would be inappropriate as they would require the aggregation of predators and prey, as well as placing detritus with invertebrates.

Interactions between variables $(+,-, 0)$ in a signed digraph are detailed in the community matrix (A). Qualitative methods of ecosystem modelling predict the response of each variable to perturbation, where perturbations are increases in the abundance of a variable. These predictions are either positive, negative, zero or ambiguous and are calculated through the use of the adjoint of the negative inverse community matrix [adj $\left(-\mathbf{A}^{-1}\right)$ ] (Dambacher et al. 2002). This matrix details the predicted response of variables to perturbation using the sign $(0,+,-)$ of response to qualitatively indicate increases and decreases to variables. In the adj $\left(-\mathbf{A}^{-1}\right)$, the predicted response is read across the rows while the variable that increased (caused the perturbation) is read down the columns (sensu Dambacher et al. 2002).

Following the simplification of a model through the aggregation of variables, the number of predictions that are consistent between the simplified (aggregated) and initial (not aggregated) model may be compared and used to assess aggregation error. We illustrate this with an example of a small food web (Fig. 2a). In this example, only 2 methods, Euclidean distance and regular equivalence, were used to aggregate the models. Aggregation using Bray-Curtis similarities follows the same methods and was therefore not included in the example. In this model, one species (3) is both a predator and a prey while another 2 species (2 and 4 ) at the same trophic level have no predators in the system. Species interactions are described in the community matrix (A) As seen in Eq. (1). The matrix of predictions [adj $\left(-\mathbf{A}^{-1}\right)$ ] is in Eq. (2) where, for example, an increase to species 2 will have a negative effect on the abundance of species 1 . The asterisks in Eq. (2) denote variables which produce incorrect predictions when aggregated using regular equivalence in Eq. (4).

$$
\begin{aligned}
& \text { Sp.1 Sp.2 Sp.3 Sp.4 Sp.5 } \\
& \mathbf{A}=\begin{array}{l}
S p .1 \\
S p .3 \\
S p .4 \\
S p .5
\end{array}\left[\begin{array}{ccccc}
- & 0 & + & 0 & 0 \\
0 & - & 0 & 0 & + \\
- & 0 & - & 0 & + \\
0 & 0 & 0 & - & + \\
0 & - & - & - & -
\end{array}\right]
\end{aligned}
$$

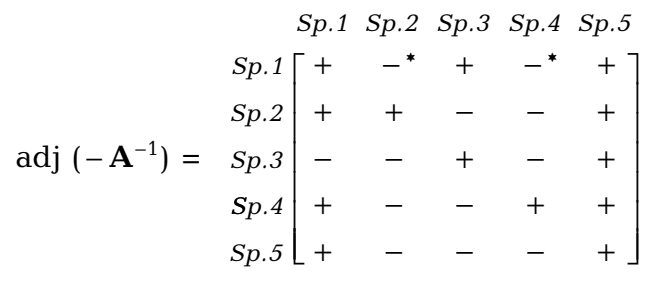

Using Euclidean distance to aggregate model variables, all middle trophic level species (2, 3 and 4) would be aggregated together (Fig. 2b) and result in the matrix of predictions seen in Eq. (3). As a result, the difference between species 3 and species 2 and 4 is not evident using this method. Dashed lines surround the aggregated species.

$$
\operatorname{adj}(-\mathbf{A})=\begin{gathered}
S p .1 \\
S p .2,3,4 \\
\hdashline S p .5
\end{gathered}\left[\begin{array}{ccc}
2 & 1 & 1 \\
-1 & 1 & 1 \\
1 & -1 & 2
\end{array}\right]
$$

In contrast, regular equivalence (Luczkovich et al. 2003) has been used in social network theory and takes both predator and prey links into account. Using this method, species 3 remained separate from species 2 and 4 (Fig. 2c). This resulted in the following matrix of predictions:

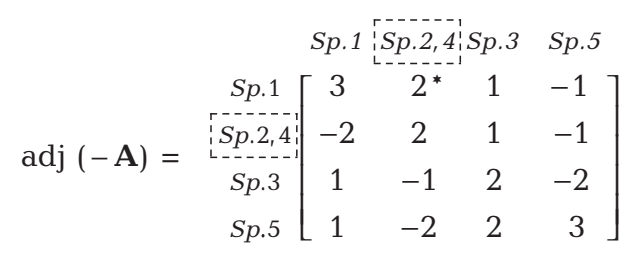

To calculate the number of predictions in the simplified models that are consistent with the detailed model, the signs $(+,-, 0)$ of the variables to be aggregated from the detailed model need to be added. The sign of the
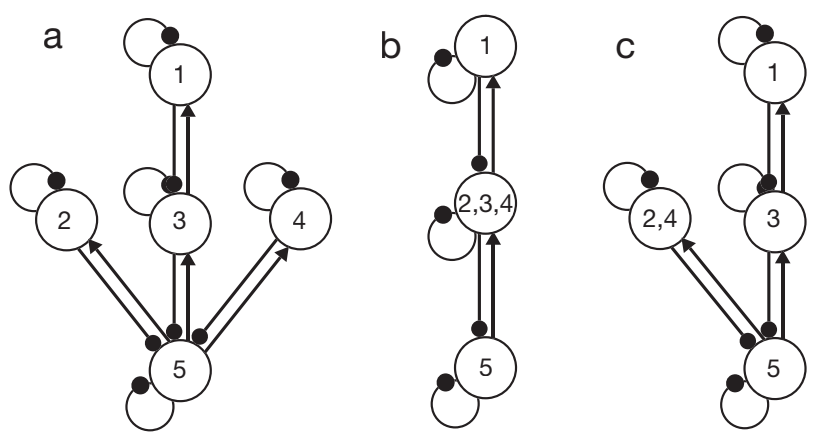

Fig. 2. (a) Example of a detailed food web model, (b) model aggregated using Euclidean distance which resulted in the aggregation of variables 2, 3 and 4, and (c) model aggregated using regular equivalence which resulted in the aggregation of variables 2 and 4 alone. Lines ending in filled circles denote negative effects; arrows: positive effects 
sum is then the correct prediction for the aggregated group. For instance, in Eq. (1), increases to species 2 and 4 (columns) create negative responses in species 1 (row) (indicated by *). As a result, the sum of these signs is also negative. In the matrix of predictions for the simplified model (Eq. 4), species 2 and 4 (column) produced a positive effect on species 1 (row) (indicated by *). The prediction in the simplified model is therefore inconsistent with the detailed model and will therefore contribute to the aggregation error.

In this study, the percent of predictions consistent with the detailed model were compared between the $\mathrm{RE}, \mathrm{BC}$ and ED models. The percentage of signs that were not consistent between the simplified and detailed model were reported as aggregation error.

\section{RESULTS}

The diets of 227 individuals from the 6 study species were examined with a total of 74 prey items identified. These prey items were placed into higher taxonomic groups (Order, $\mathrm{n}=17$ ) for inclusion in models. Minimum sample sizes for species richness were calculated using sample-based rarefaction and ranged between 10 (banded morwong) and 30 (long-snouted boarfish) individuals per species. Actual sample sizes were: banded morwong $(\mathrm{n}=62)$; bastard trumpeter ( $\mathrm{n}=44)$, blue throat wrasse $(\mathrm{n}=30)$; purple wrasse $(\mathrm{n}=24)$; long-snouted boarfish $(\mathrm{n}=41)$; and marblefish $(\mathrm{n}=26)$.

\section{Dietary analyses}

Prey items that comprised greater than $15 \% \mathrm{~W}$ have been reported as these prey species were included in the models. Details on alternative metrics and specific prey items of the study species are shown in Table 2 .

\section{Dietary overlap}

MDS clearly separated the diets of marblefish and long-snouted boarfish from those of the remaining fish species, grouped here as benthic invertebrate feeders (Fig. 3). The similarity between benthic invertebrate feeders was obvious, with clearly overlapping ellipses. Banded morwong and bastard trumpeter displayed a significant overlap due to the reliance on decapods and amphipods. This was supported with a Morisita's Index of 0.69. The dietary overlap between blue throat wrasse and purple wrasse was also significant (0.68) due to a reliance on bivalves, particularly Mytilus edulis.

\section{Ecosystem models based on dietary information}

The detailed initial model (Fig. 4) was produced on the basis of dietary information obtained during this study and information on 10 different prey groups from the published literature (Table 1, $\mathrm{n}>1710$ ). For each simplified model, variables were aggregated following the production of dendrograms (Fig. 5) with the exception of detritus. Detritus was not aggregated with any variable in the simplified models as it is functionally very different to all other model variables.

In support of the results found using Morisita's Index, aggregation of the initial model by regular equivalence split benthic invertebrate feeding fish into 2 groups: one comprised of bastard trumpeter and banded morwong, and the other containing purple and blue throat wrasses (Fig. 6a). In contrast, aggregation using Bray-Curtis similarity and Euclidean distance resulted in the grouping of purple wrasse, blue throat wrasse, banded morwong and bastard trumpeter into a single benthic invertebrate-feeding group (Fig. 6b,c). The separation of benthic invertebrate feeding fish into 2 groups retained a greater level of detail on trophic linkages. For instance, the RE model showed bivalves were a prey of wrasse but not of bastard trumpeter or banded morwong. A number of conflicting predictions occurred between models as a result of different linkages between variables in each model. For instance, wrasse have a negative effect on bastard trumpeter and banded morwong in the RE model while positive effects are produced in the BC and ED models (Table 3 ).

A comparison of predictions between the simplified and detailed initial models revealed the RE model had the largest number of predictions consistent with the initial model ( $86 \%)$ followed by the BC $(73 \%)$ and $\mathrm{ED}$ models $(65 \%)$. Examination of aggregation error allows for the discrimination of the 'best' prediction based on the initial model when conflicting predictions occur between the simplified models.

\section{DISCUSSION}

Ecosystem models are becoming more widely used in conjunction with conventional stock assessment to investigate fishery and ecosystem sustainability. The majority of ecosystem models are based on food webs (Fulton et al. 2003) and trophic information is therefore essential to facilitate their use in management. Detailed trophic information may result in complex models and incomprehensible results. Model simplification may be useful in such situations to investigate ecosystem structure and clarify results. When simplifying models through variable aggregation, aggregation error should be minimised in order to produce accurate 


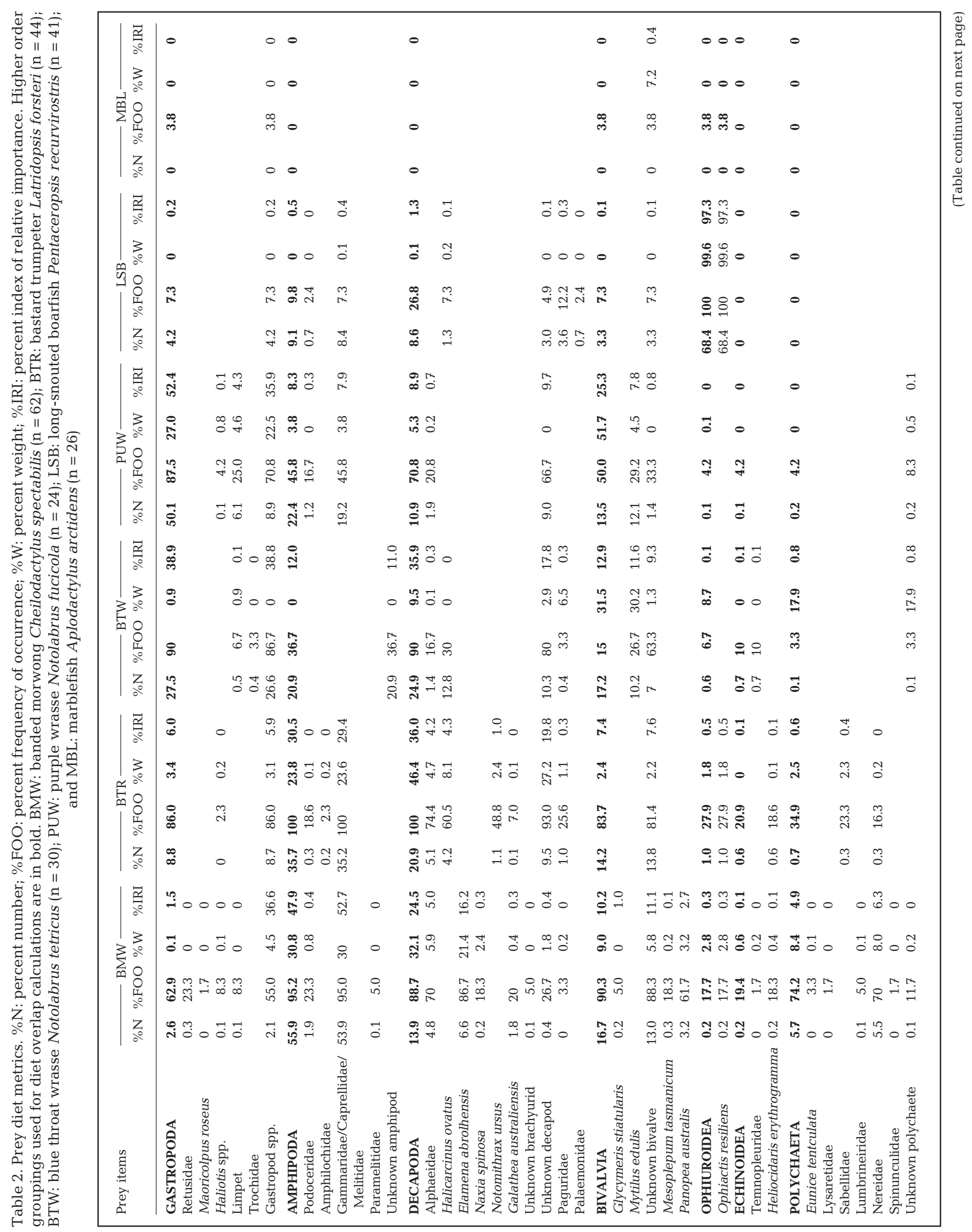




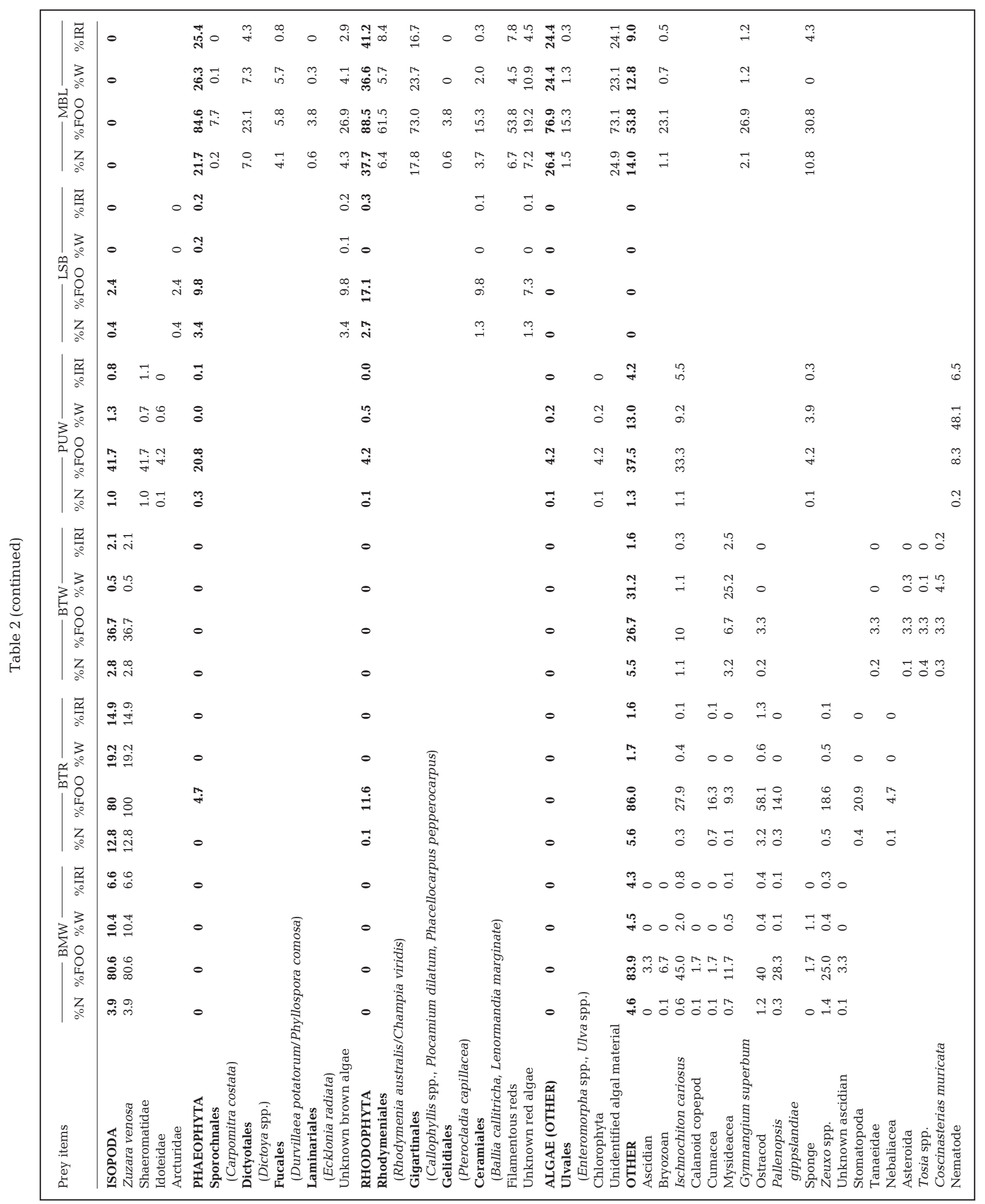




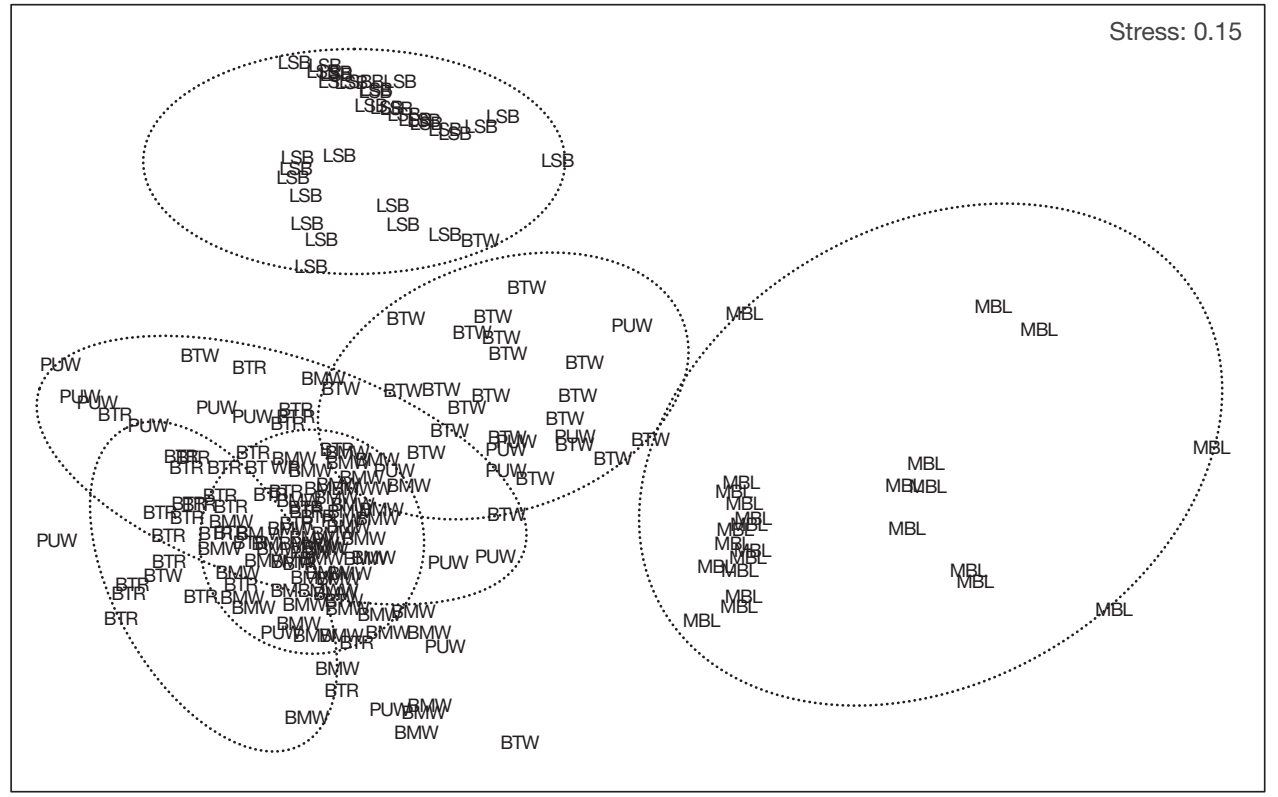

Fig. 3. MDS plot of prey item similarity for fish samples collected on the east coast of Tasmania. Each ellipse encloses almost all the specimens of one species and highlights the separation between species. MBL: marblefish Aplodactylus arctidens; LSB: longsnouted boarfish Pentaceropsis recurvirostris; BTR: bastard trumpeter Latridopsis forsteri; PUW: purple wrasse Notolabrus tetricus; BTW: blue throat wrasse N. tetricus; BMW: banded morwong Cheilodactylus spectabilis. Sample sizes are provided in the text

predictions based on the complex model. The more widespread application of qualitative modelling and the aggregation methods used in this study may prove to be beneficial for general investigations into fishery and ecosystem sustainability.

Dietary analyses are often undertaken in order to provide information and reduce the uncertainty of ecosystem linkages and properties (Deb 1997). The diets of the study species had been investigated in very few studies in the past (e.g. Fenton 1996, Bulman et al.

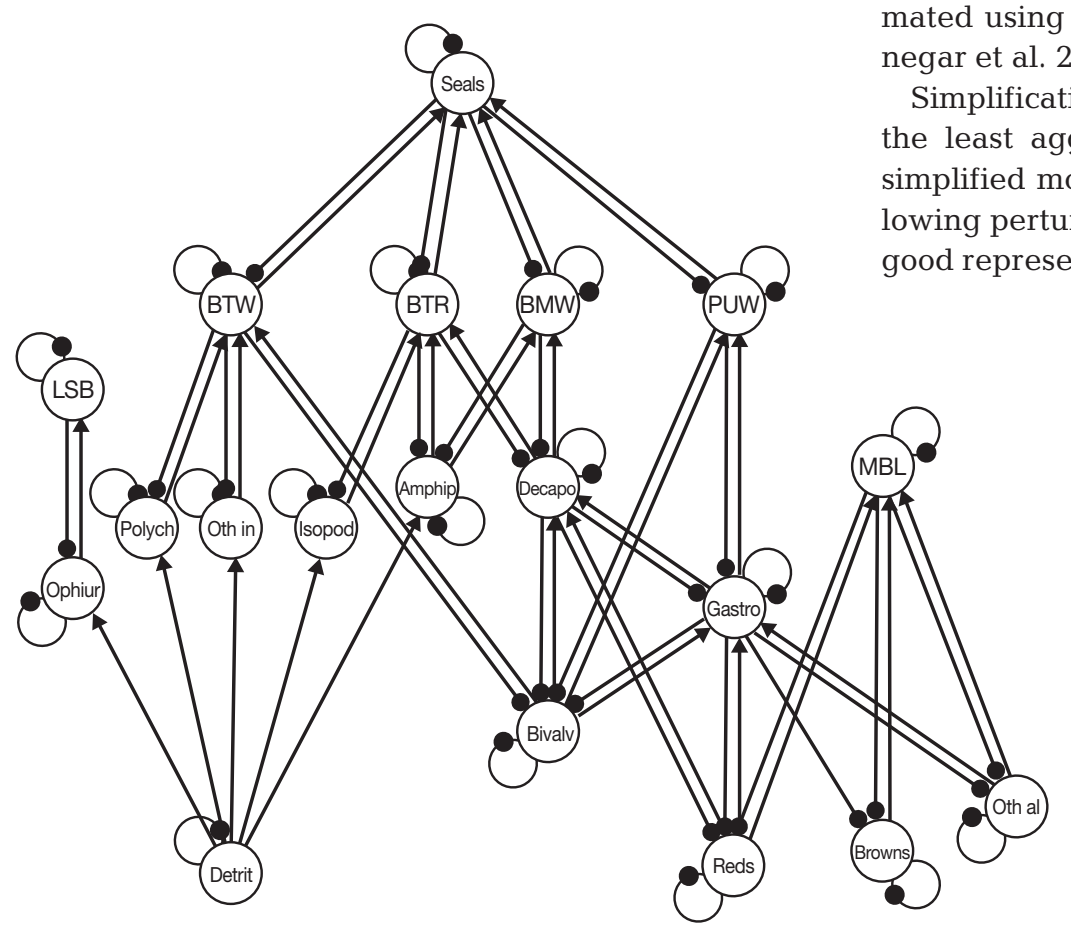

2001) and additional data collection was therefore undertaken to ensure appropriate information on each species were available from eastern Tasmania. The sample sizes used in this study were not large, however, they were bolstered by the literature and prey were grouped into higher taxonomic orders for analysis. Furthermore, it is acknowledged that identification of all trophic links is impossible (Deb 1997) and an adequate sample size was obtained to accurately identify the richness of prey items in the fish diets. The number and affect of weak links in the trophic web may be estimated using metrics, such as the Pareto $c$ Index (Pinnegar et al. 2005), during quantitative analyses.

Simplification using regular equivalence produced the least aggregation error between the initial and simplified models. The dynamics of the RE model following perturbation may therefore be assumed to be a the initial model dynamics. The RE model supported the findings of the dietary analysis and Morisita's Index by aggregating purple wrasse and blue throat wrasse, and bastard trumpeter and banded morwong. In contrast, both the BC and ED models aggregated all 4 benthic invertebrate feeding fish into

Fig. 4. Initial model with fish abbreviations as in Fig. 3. Bivalv: bivalves; Reds: red algae; Oth al: other algae; Browns: brown algae; Gastro: gastropods; Decapo: decapods; Amphip: amphipods; Ophiur: ophiuroids; Polych: polychaetes; Isopod: isopods; Oth in: other invertebrates; Detrit: detritus 


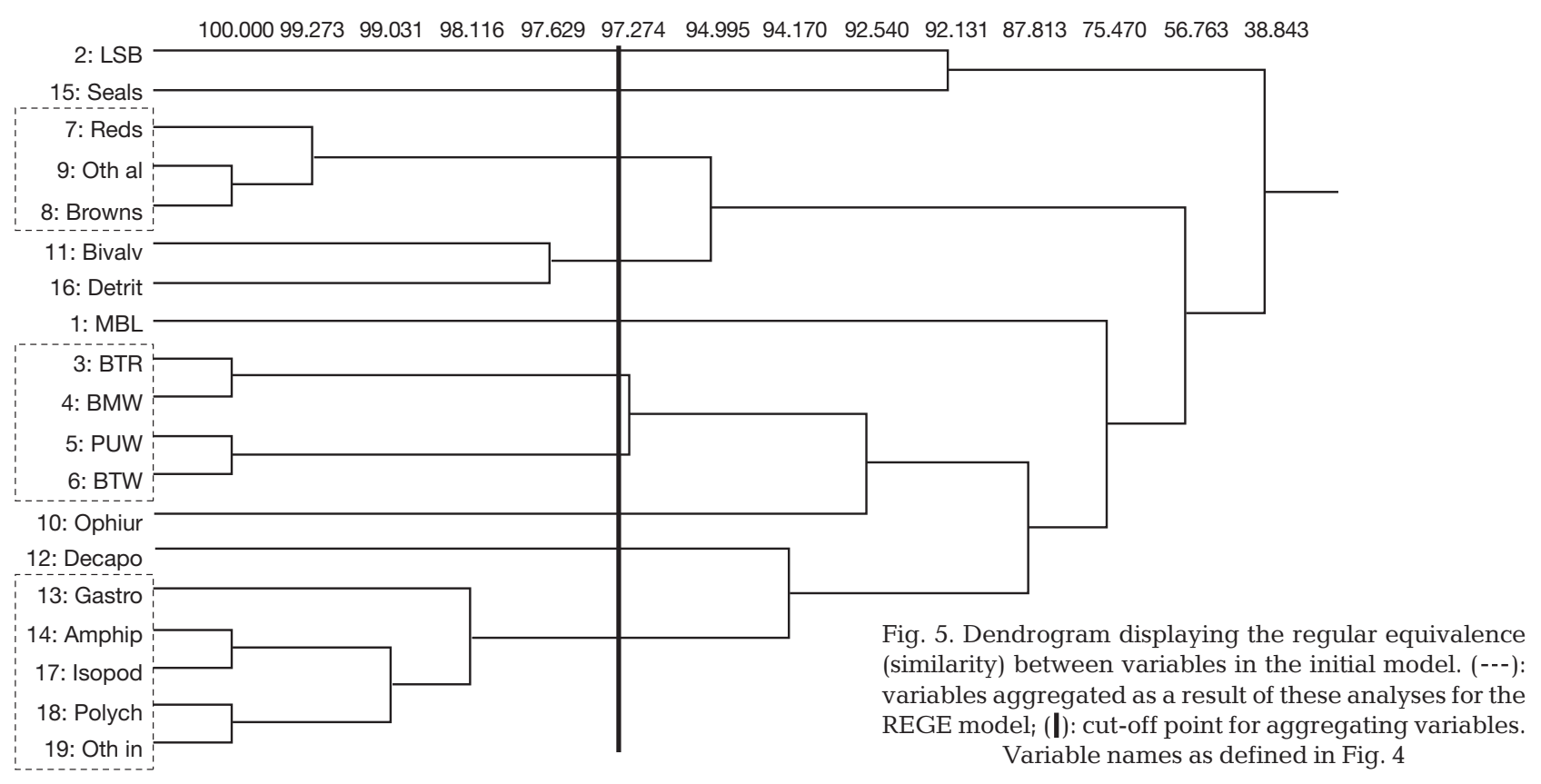

one variable. This resulted in a number of different predictions between simplified models and highlighted the importance of model structure on predictions. The RE model suggested that increases (decreases) to wrasse will have a negative (positive) effect on bastard trumpeter and banded morwong. This may indicate competition between fish groups and may also have implications for the commercial wrasse and banded morwong fisheries. For instance, substantial increases in the catch rate of wrasse may reduce the negative effect of wrasse and allow banded morwong to increase in abundance. Aggregating these 2 fish variables together in the $\mathrm{BC}$ and $\mathrm{ED}$ models did not allow for the determination of these negative effects.
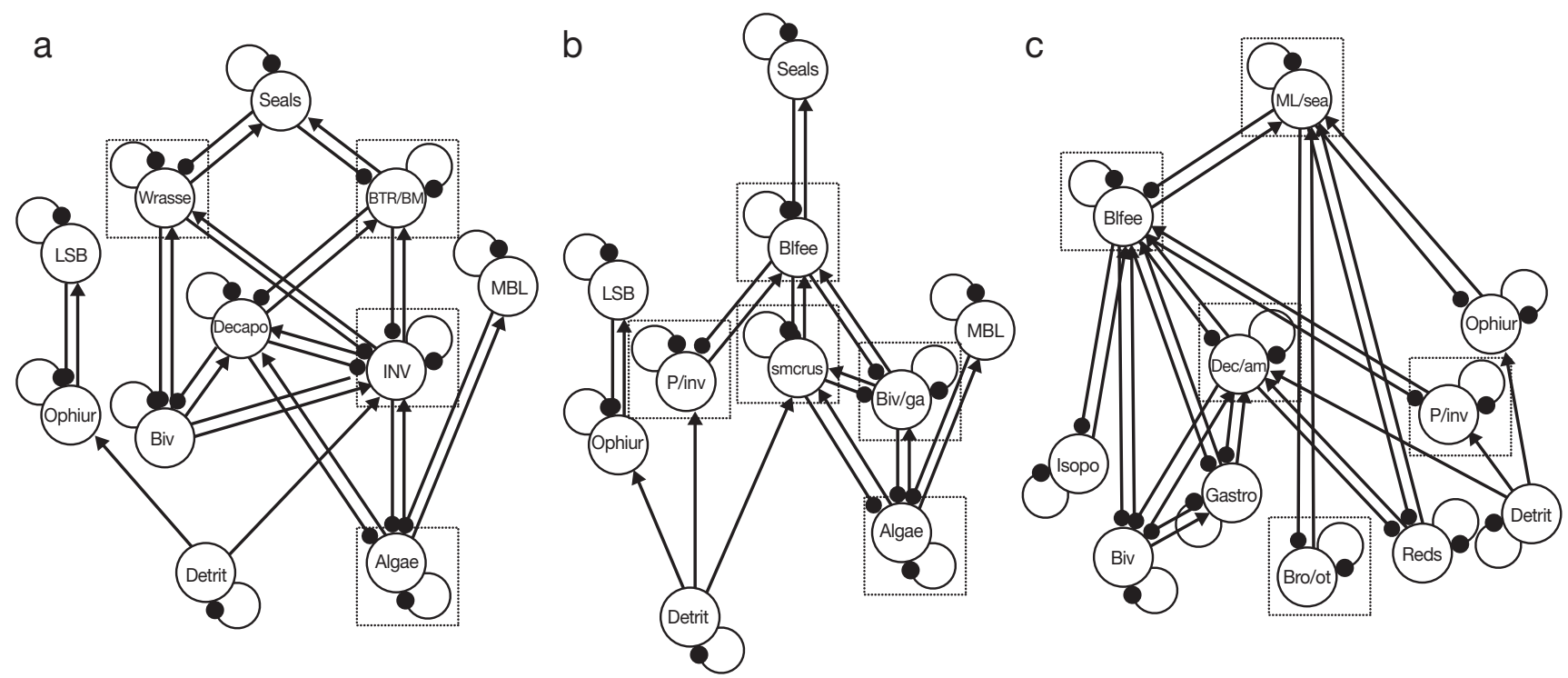

Fig. 6. (a) RE, (b) BC and (c) ED models as simplified from the initial model in Fig. 4. (.......): aggregated variables from Fig. 4 following aggregation. BTR/BM: bastard trumpeter and banded morwong; Wrasse: purple wrasse and blue throat wrasse; BI fee: banded morwong, bastard trumpeter, blue throat wrasse and purple wrasse; INV: isopods, polychaetes, other invertebrates, amphipods and gastropods; Algae: red, brown and other algae; P/inv: polychaetes and other invertebrates; smcrus: decapods, isopods and amphipods; Biv/ga: bivalves and gastropods; Bro/ot: brown algae and other algae; Dec/am: decapods and amphipods; ML/sea: marblefish, long-snouted boarfish and seals 
Table 3. Selected conflicting predictions of response to perturbation (increase to a variable) for models aggregated using regular equivalence (RE), Bray-Curtis similarities (BC) and Euclidean distance (ED). Where variable names were not the same between models the equivalent name has been given. See Figs. 4 \& 6 for explanations of abbbreviations. Effects are: negative (-); positive (+); no effect (0); and ambiguous (?) when the effect may be positive or negative

\begin{tabular}{|c|c|c|c|c|c|c|c|c|}
\hline \multirow{2}{*}{$\begin{array}{l}\begin{array}{l}\text { Variable } \\
\text { increased }\end{array} \\
\text { Wrasse }\end{array}$} & \multirow{2}{*}{$\begin{array}{l}\text { - RE model } \\
\begin{array}{l}\text { Variable } \\
\text { affected }\end{array}\end{array}$} & \multirow{2}{*}{$\begin{array}{c}\text { Response } \\
-\end{array}$} & \multirow{2}{*}{$\begin{array}{l}\begin{array}{l}\text { Variable } \\
\text { increased }\end{array} \\
\begin{array}{l}\text { Benthic invert. } \\
\text { feeders (BI fee) }\end{array}\end{array}$} & $\begin{array}{c}\text { BC model } \\
\text { Variable } \\
\text { affected }\end{array}$ & Response & \multirow{2}{*}{$\begin{array}{l}\begin{array}{l}\text { Variable } \\
\text { increased }\end{array} \\
\begin{array}{l}\text { Benthic invert. } \\
\text { feeders (BI fee) }\end{array}\end{array}$} & $\begin{array}{c}\text { ED model } \\
\text { Variable } \\
\text { affected }\end{array}$ & Response \\
\hline & & & & $\begin{array}{l}\text { Benthic invert. } \\
\text { feeders }\end{array}$ & + & & $\begin{array}{l}\text { Benthic invert. } \\
\text { feeders }\end{array}$ & + \\
\hline Wrasse & Bivalves & - & $\begin{array}{l}\text { Benthic invert. } \\
\text { feeders }\end{array}$ & $\begin{array}{l}\text { Benthic invert. } \\
\text { feeders }\end{array}$ & $?$ & $\begin{array}{l}\text { Benthic invert. } \\
\text { feeders }\end{array}$ & Bivalves & + \\
\hline BTR/BM & Wrasse & - & $\begin{array}{l}\text { Benthic invert. } \\
\text { feeders }\end{array}$ & $\begin{array}{l}\text { Benthic invert. } \\
\text { feeders }\end{array}$ & + & $\begin{array}{l}\text { Benthic invert. } \\
\text { feeders }\end{array}$ & $\begin{array}{l}\text { Benthic invert. } \\
\text { feeders }\end{array}$ & + \\
\hline $\begin{array}{l}\text { Invertebrates } \\
\text { (gastropods) }\end{array}$ & Bivalves & - & $\begin{array}{l}\text { Bivalves/ } \\
\text { gastropods } \\
\text { (Biv/ga) }\end{array}$ & Bivalves & + & Gastropods & Bivalves & - \\
\hline Seals & MBL & - & Seals & MBL & - & $\begin{array}{l}\text { Marblefish/ } \\
\text { seals (ML/sea) }\end{array}$ & Marblefish (MBL) & + \\
\hline Ophiuroids & $\begin{array}{l}\text { All variables } \\
\text { exept Ophiur } \\
\text { and LSB }\end{array}$ & $\begin{array}{ll}\mathrm{s} & 0 \\
\mathrm{ar} & \end{array}$ & Ophiuroids & $\begin{array}{l}\text { All variables } \\
\text { exept Ophiur } \\
\text { and LSB }\end{array}$ & 0 & Ophiuroids & $\begin{array}{l}\text { All variables } \\
\text { exept Ophix } \\
\text { and Long- } \\
\text { snouted boarfish } \\
\text { (LSB) }\end{array}$ & $\begin{array}{l}\text { lixed effects } \\
\text { or -) except } \\
\text { Detrit (0) }\end{array}$ \\
\hline
\end{tabular}

Bray-Curtis similarities do not take the predators of the species into account during calculations. This was illustrated by the BC model where gastropods were aggregated with their bivalve prey. It has been suggested that predators and their prey should not be aggregated in many studies (O'Neill \& Rust 1979, Gardner et al. 1982, Fulton et al. 2003) as this increases the error of the model. As a result, aggregating gastropods and bivalves affected model predictions. The BC model predicted a positive effect of gastropods on bivalves because they form part of the same variable and are therefore assumed to increase in abundance simultaneously. In contrast, the RE and ED models retained bivalves and gastropods as separate variables and this resulted in negative effects on bivalves as a result of gastropod predation. Similarly, the simplification of the initial model using Euclidean distance resulted in the aggregation of seals with members of a lower trophic level: marblefish and long-snouted boarfish. Although seals were not included as direct predators on these fish species, aggregating members of different trophic levels creates error as shown with gastropods and bivalves. This aggregation may also create error as a consequence of variables with different production and turnover rates being placed in a single variable (O'Neill \& Rust 1979, Gardner et al. 1982).

Bray-Curtis and Euclidean distance measures do not take all 'neighbours' (i.e. predators and prey) into account when calculating similarities and this results in aggregation error. Long-snouted boarfish and ophiuroids formed a separate subsystem in the initial model as they were only connected to the rest of the system through a one-way link with detritus. Variables in separate subsystems only affect each other and can not be affected by alterations in the abundance of variables in the rest of the system. This detail was retained in both the RE and BC models, however, the aggregation of seals with marblefish and long-snouted boarfish in the ED model connected ophiuroids to the rest of the system. This contributed to the high level of error in the ED model and occurred because Euclidean distance did not account for different prey types and linkages in the system.

As models become more important in resource management around the world, the problem of uncertainty in model prediction is increasing. In order to produce constructive and sustainable management regimes, ecosystem models need to be based on information specific to the study at hand. The results of the dietary analyses in this study allowed the production of alternative qualitative models from which aggregation error and model structure were investigated. It is important that techniques for model aggregation should be based on the similarity of all neighbours (e.g. predators and prey) as well as factors such as life history characteristics. In the past, regular equivalence has generally only been used in studying social networks (Luczkovich et al. 2002). Future studies should use the methods outlined in this study in order to simplify models, minimise aggregation error and increase model predictability prior to further ecosystem analyses. 
Acknowledgements. Thanks to fisherman M. Cuthbertson for many days in the field and continued willingness to help. H. Pederson, J. Hulls, G. Ewing, S. Tracey, T. Probst and T. Alexander provided much needed field assistance. Assistance with taxonomic identification was provided by A. Hirst, G. Edgar, N. Barrett and J. Valentine. Thanks to D. McLeod for ideas on dietary analysis. Three anonymous reviewers provided useful feedback that improved an earlier version of this manuscript.

\section{LITERATURE CITED}

Auger P, Charles S, Viala M, Poggiale JC (2000) Aggregation and emergence in ecological modelling: integration of ecological levels. Ecol Model 127:11-20

Bray JR, Curtis JT (1957) An ordination of the upland forest communities of southern Wisconsin. Ecol Monogr 27: 325-349

Bulman CM, Althaus F, He X, Bax NJ, Williams A (2001) Diets and trophic guilds of demersal fishes of the south-eastern Australian shelf. Mar Freshw Res 52:537-548

Bulman CM, Condie S, Furlani D, Cahill M, Klaer N, Goldsworthy SD, Knuckey I (2006) Trophic dynamics of the eastern shelf and slope of the South East Fishery: impacts of and on the fishery. Project no. 2002/028, Final report for Fisheries Research and Development Corporation. CSIRO Marine and Atmospheric Research, Hobart

Cale WG, O'Neill RV, Gardner RH (1983) Aggregation error in nonlinear ecosystem models. J Theor Biol 100:539-550

> Choat JH, Clements KD (1992) Diet in odacid and aplodactylid fishes from Australia and New Zealand. Aust J Mar Freshw Res 43:1451-1459

Christensen V, Pauly D (1992) Ecopath-II- A software for balancing steady-state ecosystem models and calculating network characteristics. Ecol Model 61:169-185

Christensen V, Guenette S, Heymans JJ, Walters CJ, Watson R, Zeller D, Pauly D (2003) Hundred-year decline of North Atlantic predatory fishes. Fish Fisheries 4:1-24

Colwell RK, Mao CX, Chang J (2004) Interpolating, extrapolating and comparing incidence-based species accumulation curves. Ecology 85:2717-2727

Cortes E (1997) A critical review of methods of studying fish feeding based on analysis of stomach contents: application to elasmobranch fishes. Can J Fish Aquat Sci 54: 726-738

Dambacher JM, Li HW, Rossignol PA (2002) Relevance of community structure in assessing indeterminacy of ecological predictions. Ecology 83:1372-1385

Deb D (1997) Trophic uncertainty vs. parsimony in food web research. Oikos 78:191-194

Edgar G (2000) Australian marine life: the plants and animals of temperate waters. New Holland Publishers, Sydney

FAO Fisheries Department (2004) The state of world fisheries and aquaculture (SOFIA). FAO, Rome

Fenton GE (1996) Diet and predation of Tenagomysis tasmaniae Fenton, Anisomysis mixta australis (Zimmer) and Paramesopodopsis rufa Fenton from south-eastern Tasmania (Crustacea: Mysidacea). Hydrobiologia 323:31-44

Fulton EA, Smith ADM, Johnson CR (2003) Effect of complexity on marine ecosystem models. Mar Ecol Prog Ser 253: $1-16$

Gardner RH, Cale WG, O'Neill RV (1982) Robust analysis of aggregation error. Ecology 63:1771-1779
Holloway MG, Keough MJ (2002) An introduced polychaete effects recruitment and larval abundance of sessile invertebrates. Ecol Appl 12:1803-1823

> Horn HS (1966) Measurement of 'overlap' in comparative ecological studies. Am Nat 100:419-424

Hume F, Hindell MA, Pemberton D, Gales R (2004) Spatial and temporal variation in the diet of a high trophic level predator, the Australian fur seal (Arctocephalus pusillis doriferus). Mar Biol 144:407-415

Hyslop EJ (1980) Stomach contents analysis: a review of methods and their application. J Fish Biol 17:411-429

- Iwasa Y, Andreasen V, Levin SA (1987) Aggregations in model ecosystems. I. Perfect aggregation. Ecol Modell 37: 287-301

Iwasa Y, Levin SA, Andreasen V (1989) Aggregation in model ecosystems. II. Approximate aggregation. IMA J Math Appl Med Biol 6:1-23

- Levins R (1974) The qualitative analysis of partially specified systems. Ann NY Acad Sci 231:123-138

Levins R (1975) Evolution in communities near equilibrium. In: Cody ML, Diamond JM (eds) Ecology and evolution of communities. Harvard University Press, Cambridge, MA, p $16-50$

Lisbjerg D, Petersen JK (2000) Clearance capacity of Electra bellula (Bryozoa) in seagrass meadows of Western Australia. J Exp Mar Biol Ecol 244:285-296

Luczkovich JJ, Ward GP, Johnson JC, Christian RR, Baird D, Neckles H, Rizzo WM (2002) Determining the trophic guilds of fishes and macroinvertebrates in a seagrass food web. Estuaries 25:1143-1163

> Luczkovich JJ, Borgatti SP, Johnson JC, Everett MG (2003) Defining and measuring trophic role similarity in food webs using regular equivalence. J Theor Biol 220: 303-321

Muñoz AA, Ojeda FP (1998) Guild structure of carnivorous intertidal fishes of the Chilean coast: implications of ontogenetic dietary shifts. Oecologia 114:563-573

Okey TA, Banks S, Born AF, Bustamante RH and others (2004) A trophic model of a Galapagos subtidal rocky reef for evaluating fisheries and conservation strategies. Ecol Model 172:383-401

O'Neill RV, Rust BW (1979) Aggregation error in ecological models. Ecol Model 7:91-105

Pinnegar JK, Blanchard JL, Mackinson S, Scott RD, Duplisea DE (2005) Aggregation and removal of weak-links in foodweb models: system stability and recovery from disturbance. Ecol Model 184:229-248

Puccia CJ, Levins R (1985) Qualitative modeling of complex systems: an introduction to loop analysis and time averaging. Harvard University Press, Cambridge, MA

Raffaelli D, Hall SJ (1992) Compartments and predation in an estuarine food web. J Ecol 61:551-560

Raick C, Soetaert K, Gregoire M (2006) Model complexity and performance: How far can we simplify? Prog Oceanogr 70: 27-57

Sokal RR, Sneath PHA (1963) Principles of numerical taxonomy. Witt Freeman and Co, San Francisco, CA

Wallace RK, Ramsey JS (1983) Reliability in measuring diet overlap. Can J Fish Aquat Sci 40:347-351

Woods CMC (1993) Natural diet of the crab Notomithrax ursus (Brachyura, Majidae) at Oaro, South Island, New Zealand. NZ J Mar Freshw Res 27:309-315

Yodzis P (2001) Must top predators be culled for the sake of fisheries? Trends Ecol Evol 16:78-84 